plan aleo adopted by Mr. Brichsen) is al ways a useful hand, which cannot be said for the hand with the phalanx as an obstruction.*

K.

\section{Oringinal Communirations.}

\section{CASE OF IDIOPATHIC TETANUS.}

By Thomas L. Pridham, Esq., Bideford, Devon.

Constantins Bowman, aged 27 years, the subject of the following interesting case of tetanus, had suffered from a low epidemic fever, which had prevailed in this district about six weeks prior to his present attack, during which he had considerable hremorrhage from his bowels. He recovered slowly, and on the 19th of the present month he went to his work in tolerable condition; but he was weak, and not able to do much. During the day he drank two half-pints of Stogumber beer.

Early on the morning of the 20th, I was requested to visit him. Having inquired of the person who came for me, who appeared an intelligent man, somewhat of his state, I forwarded by him a draught containing thirty drops of tincture of henbane in camphor mixture. I visited him two hours afterwards, which was at six o'clock. I found, after taking the draught I had sent, that he had slept; and, at the time I saw him, he was perfectly quiet and reasonable, complaining only of a serere pain in the back of his head. He told me he had gone to bed apparently perfectly well, having eaten a meat supper, with bread, but no kind of stimulus was taken; that he awoke between three and four o'clock, with a sensation of shaking of his limbs, which he could not control, and a pain at the back of the head and a little down the spine. He said his feelings and ideas soon became uncontrollable, and he felt a great desire to destroy himself, his wife, and child. His breathing was oppressed. He told me he had repeatedly struck his head against the bed, and once against the wall, in which there was an evident mark; for so violent had he been that the laths and plaster had been driven in correspondingly with the size of his head. His great desire was to strike his head where he suffered the most pain, saying that he should then be well. He further remarked, that his head became drawn back, his heels drawn up, his jaw fixed, and his hands clenched. His account of himself and what had passed was confirmed by his wife and those persons whom she had called to her assistance. The attack lasted one hour. When I saw him, his pulse was 76 , soft, and free; tongue moist and slightly coated. The pain in the region of the occiput still continued. I ordered an active aperient, and left him.

Two hours afterwards, I was again summoned to visit him. The messenger informed me that Bowman had been again seized as in the early morning. At the time I visited him, he was in a tetanic state; head drawn back; heels drawn backwards and upwards; jaw fixed; hands clenched; respiration slow; pulse 96 ; eyes with a strange and wild expression, pupils much dilated; intense pain under the occiput and down the neck; heat about the head. The bowels had been acted on freely. Mustard poultices were ordered to the spine, soles of the feet, and calves of the legs; tha hair to be removed, and cold to be applied to the head, and a large blister to the back of the neck. I learnt that, before the tetanic spasms had come on, he had been restrained, as the efforts to commit violence on himself and others had been very great. This attack lasted about two hours, and it left the patient quite exhausted and weak, with a sensation of numbness of the lower extremities. As soon as he was able to swallow, I gave him sixty drops of tincture of henbane in camphor mixture, and further

- A most interesting operation of this kind was also performed by Mr. Marshall at University College Hospital, on May 28th, iu a case in which excessive hemorrhagic diathesis existed. The finger was removed by the gulvanic cantory. prescribed three grains of calomel with ten drops of liquor opii sedativus, to be taken every three hours.

Another attack of equal severity came on twelve hours. Another attack of equal sererill continued. The blister was ardered to be dressed with mercurial ointment.

The fourth attack came on at the end of another twelre hours. It was not, howerer, quite so severe as the former ones; but still the same stages of the disease, with the deones; but still the same stages of the disease, with the commit violence, were present. During the intervals of the attack, he spoke of his feelings prior to, at the time of, and subsequent to, the attack. He said that, when the spasms were on him, he was exceedingly impatient of rethe spasms were straint, and had the desire to commit violence; that his breathing was oppressed during his tetanic state. His attendants remarked that they knew when the attack was coming, by marked that they knew when the attack was co that some one would hold his hands, to prevent his striking either the parson (who was present) or the doctor.

I watched the case closely for twenty-four hours longer, during which time he was attacked twice; but the attacks gradually diminished in severity; and as his gums became sore so in proportion did the disease appear to subside. He took in the whole about sixty grains of calomel. Indications of the disease, however, made their appearance at the intervals of each returning period of twelve hours for two days. He is now, on the 30 th of the month, rapidly recovering; appetite good; tongue clean; pulse 70 , soft and free. He sleeps well, and expresses himself grateful for having been relieved from so frightful an attack, during which, he says, he nerer lost his sense of consciousness, and recollects everything that has passed.

REMARKs. The events which have been passing during the last fortnight in the Central Criminal Court in London induce me to send this case for publication in the Associa tion JoukNAI, as it will certainly add to those cases already published of idiopathic tetanus which closely resemble those of the traumatic form. It forcibly reminds me of two cases of traumatic tetanus which I have seen in private practice, caused by injury inflicted on the body by accidents; nor can it be denied that it resembles in many particulars those cases of tetanus which have of late been described as occurring after taking the deadly poison of strychnia into the stomach. In Bowman's case there is not the slightest suspicion of poison being taken, or of injury sustained. The uncontrollable desire to destroy life on the approach of an attack is remarkable, and interesting to those who regard phrenology as a science.

In conclusion, I have to remark that Bowman is of a peculiarly anxious and nervous temperament. He was, moreover, somewhat in difficulties, in consequence of his long illness; and this circumstance appeared to press heavily upon his mind; and it is more than probable that the small amount of stimulus which he had taken in his labour acted on an irritable and excited brain, producing congestion, and it may be, to a certain extent, inflammation about its the base: and hence the train of symptoms which I have described, which evidently yielded to the prescribed treatment. My medical friend, Mr. Thompson, saw the case with me.

\section{NOTES ON THE PATHOLOGY AND TREATMENT OF ULCERS OF THE LEG.}

By JoHN KENT SPENDER, Esq., Surgeon to the Eastern Dispensary, Bath. [Concluded from page 364 .]

Geseral principles of treatment, like all other rules, admit of some exceptions, and require some modifications in practice. The instances in which the plan of chalky incrustation and compression has answered most completely are superficial ulcerations, however extensive the surface may be, and whether dependent on varix or not. There is less destruction of parts, and consequently less demand upon the reparatory processes. Then it will generally be 